\title{
Do You Imitate Immediately? The Location Choices for Foreign Direct Investment
}

\author{
Hsien-Jui Chung ${ }^{1}$, Wei-Wan Liao ${ }^{2}$, Chad Lin $^{3}$ \\ ${ }^{I}$ National Chung Cheng University, \\ 1, University Rd., Minhsiung \\ Chaiyi 621, Taiwan \\ E-mail:hjchung@ccu.edu.tw \\ ${ }^{2}$ National Chi Nan University, \\ 470, University Rd., Puli \\ Nantou 545, Taiwan \\ E-mail: cf002@ms49.hinet.net \\ ${ }^{3}$ Curtin University \\ Curtin Health Research Campus, 10 Selby Street, Shenton Park, WA 6008, Australia \\ E-mail: elin123au@yahoo.com.au/c.lin@curtin.edu.au
}

\begin{abstract}
This study applies recency effect on interfirm imitation behavior to investigate whether recent location choices of peer firms regarding foreign direct investment (FDI) exert imitation pressure on another firm's FDI location choices. This study examines the FDI data of listed companies in Taiwan. The results confirm the existence of recency effect. This study further indicates that the remote experience peer firms and a firm's own experience have negative moderating effects on recency effect.
\end{abstract}

Keywords: Foreign Direct Investment, Imitation, Matthew Effect, Recency Effect.

\section{Introduction}

Imitation is a crucial mechanism that drives firms to take actions. ${ }^{1}$ Although the action decisions firms intend to make are highly uncertain and complex, the actions of peer firms often provide valuable decision cues. If the causal relationship between actions and their consequences is unclear, firms would more likely rely on whether peer firms have taken similar actions to make decisions. ${ }^{2}$ The experience of peer firms provides other firms with information about customer needs and preferences for distinguishing market opportunities at lower risk. ${ }^{3,4}$ Thus, imitation behavior is more likely to occur.

Many studies have observed that not all moves yield the same imitation effects. For instance, Gimeno et al. $(2005)^{5}$ observed that the moves made by firms with higher domestic market shares yield stronger imitation effects. This study, based on the concept of the recency effect in cognitive psychology, explores imitation effects that resulted because of the recent moves made by peer firms. A recency effect means that events occurring recently would attract more attention from decision makers and would thus have stronger beliefadjustment effects. Studies on the decisions of jurors (e.g., Ref. 6) and auditors (e.g., Ref. 7) have confirmed the existence of recency effect.

Regarding the action decisions of firms, awareness is the premise of action. ${ }^{8}$ According to recency effect, recently occurring events can stir the awareness of firms to a certain degree; therefore, they are more likely to yield significant imitation effects. However, imitation effects associated with the recent moves of peer firms is an issue that has not received sufficient attention in previous studies on the imitation behavior of firms. 
Thus, this study, based on the concept of the recency effect, examines imitation effects yielded from the recent moves of peer firms.

Another issue often neglected in imitation studies is the "Matthew effect", which is a phenomenon of unequal initial conditions leading to greater subsequent inequality because of the positive feedback effect. Studies on scholar reputation, ${ }^{9}$ standard rivalry, ${ }^{10}$ and network externality (e.g., Ref. 11), have reported effects similar to the Matthew effect. Applying the concept of the recency effect to imitation studies suggests that a recent increase in the number of firms making a certain type of move would result in imitative pressure that would drive other firms to follow and make the same type of move in the current period, thereby leading to stronger imitative pressure in the next period, as the Matthew effect depicts. Hence, firms in the same industry would converge to a certain type of move and become highly homogenous. However, in many industries, various types of moves coexist, implying the absence of the convergence of moves. Hence, this study investigates the situations under which the Matthew effect would not occur by introducing two factors that weaken the recency effect: peer firms' remote moves and a firm's own experience. These two factors would influence how a firm perceives and interprets peer firms' recent moves, the likelihood of imitation, and finally the probability of occurrence of the Matthew effect. Such an examination contributes to a deliberate understanding of the imitation process in a populationlevel study.

This study investigates the location choices of firms for establishing foreign subsidiaries as observation targets. The process for establishing foreign subsidiaries often involves unusual uncertainty and complexity; therefore, firms in such situations often refer to the moves made by peer firms. The influences and experiences of imitation have been verified as critical factors regarding the location choices of firms for foreign direct investment (FDI). Because it is often difficult to evaluate the performance of each FDI, a firm considers the experience of peer firms as a crucial reference point, particularly when it lacks operating experience in a specific country in which many firms simultaneously invest. This study explores the impacts of the recent moves of peer firms on the current choices made by a firm, the moderating impacts of the remote moves of peer firms, and a firm's own experience on the recency effect in a sample of Taiwanese listed firms regarding location choices for FDI.

\section{Theory and Hypothesis}

\subsection{Imitation and uncertainty}

Imitation is an essential behavioral pattern. The psychologist Thorndike (1898) ${ }^{12}$ defined imitation as "learning to do an act from seeing it done." This definition suggests that imitation can be viewed as a social process through which individuals engage in tasks by observing the actions made by peers. Because the imitation process remains in place, individuals generally engage in a specific type of action if they notice that such an action is widely adopted.

The notion of imitation has been widely applied in research on firm behavior (e.g., Ref. 13, 14 \& 15). One of the core premises of applying an imitation perspective to studying the actions of organizations is that a firm would observe whether peer firms adopt specific moves. Their adoption decisions often constitute a convenient type of information for the firm to decide whether it would make the same moves. ${ }^{15}$ If the causal relationship between a move and its performance consequence is unclear, then firms are more likely to refer to the moves of peer firms for making decisions. ${ }^{2,16,17}$ Therefore, imitation behavior is more likely to occur.

Entering a foreign market is often accompanied by a high degree of uncertainty; to reduce uncertainty, firms seek to learn from the experience of peer firms. ${ }^{18}$ Many studies on international expansion have observed that frequency-based imitations would appear when firms make location choices, meaning that when the number of firms in the same industry investing in a specific country increases, a firm would be more likely to invest in that country. 17,19

\subsection{Recency effect of peer firms' moves}

Recency effect is a type of order effect. Order effects are in place when two events, $\mathrm{A}$ and $\mathrm{B}$, appearing in different sequences ( $\mathrm{A}$, then $\mathrm{B}$; and $\mathrm{B}$, then $\mathrm{A}$ ) result in different judgments. ${ }^{20}$ Regarding the order effects, if events occurring later significantly influence decision makers' beliefs, thus influencing their judgments, recency effect is in place. Recency effect has been observed in many situations related to decision-making. 
Ashton and Ashton (1988) ${ }^{21}$, Asare (1992) ${ }^{22}$, and Reckers and Schultz (1993) ${ }^{7}$ verified the existence of recency effect by conducting studies on evaluations by auditors and accountants on internal control systems of corporations. Kerstholt and Jackson (1998) ${ }^{6}$ observed that new pieces of information have a significant impact on jurors' judgments because they make judgments as they receive each piece of information. In a study on mock trials, Furnham (1986) ${ }^{23}$ found that the judgment of guilt is also influenced by new information.

Recency effect can also be inferred from the attention-based view of the firm, ${ }^{24}$ which argues that a firm's behavior results from how firms distribute their attention. Events that receive more attention yield greater imitation effects. In comparison with remote events, recent events often receive more attention. ${ }^{25}$ Therefore, recent moves made by peer firms can yield stronger imitation effects.

Recency effect is more likely to occur when decision makers face complex decisions. ${ }^{20}$ Firms must consider complex factors in determining the location of FDI. FDI location choices reflect not only firms' considerations of their own strengths and weaknesses but also their judgments regarding markets, suppliers, and the appropriate ways of positioning foreign subsidiaries in global competition. Therefore, evaluating the locations of foreign subsidiaries, which includes numerous types of information, is highly complex. Therefore, recency effect are more likely to occur because of the limited cognitive- and informationprocessing capabilities of the decision makers. ${ }^{20}$ When the FDI of peer firms in a specific country booms in the recent period, a firm would pay close attention and consider whether the country is a suitable investment target. Greater attention results in greater likelihood that a firm would invest in the targeted country. Hence, the following hypothesis is proposed:

Hypothesis 1(H1): The greater the amount of recent FDI by peer firms in a specific country, the more likely it is that a firm would have new FDI in that country in the current year.

\subsection{Moderating the effects on recency effect: attention and firms' own experience}

According to recency effect, recent moves made by peer firms have significant impacts on the judgments of decision makers. However, such impacts can be moderated by factors such as attention to recent events and firm's own experience.

First, attention is a critical factor causing the recent moves of peer firms result in imitation effects. The principle of situated attention suggests that the amount of attention given to a specific action depends on the particular situation that the decision maker is in. ${ }^{26}$ According to this principle, attention aroused by the same number of recent events would vary with the context of recent events. The belief-adjustment model $^{20}$ suggests that new information adjusts existent beliefs about targeted decisions. If a specific type of event occurred consistently in the past, the degree of newness of the same event occuring recently would be lower. By contrast, if a specific type of event occurred rarely in the past, the same event occurring recently would appear to be much newer, thus attracting more attention from decision makers.

Therefore, a specific type of event occurring consistently in the past in an industry indicates that similar events are routine-like actions or decisions. By contrast, if there are few similar past events in an industry, recent events would seem to be non-routine events. Because non-routine events are more likely to attract attention, ${ }^{27}$ unprecedented recent events are more likely to be noticed.

Thus, the number of recent FDIs that peer firms had in a specific location affects how much attention the location can receive from a firm. If peer firms had many past FDIs in the location, their recent investment in the location cannot attract much attention. Therefore, the probability that a firm will invest in that location decreases. If the recent FDI of peer firms in a location is unprecedented, such investments will attract more attention. A firm will try to find a reason why peer firms have engaged in this FDI location where there have been few investments e. Consequently, a firm will be more likely to invest in that location. Thus, Hypothesis 2 is proposed.

Hypothesis 2(H2): The amount of peer firms' remote FDI in the location will negatively moderate $H 1$.

Another factor that has moderating impacts on recency effect is the experience of decision makers. Because experienced decision makers are more confident about their judgment than inexperienced 
ones $^{28}$, recent events would have less impact on them. Many studies on auditors' evaluation of the financial reports of the companies confirm that the experience of the decision makers decreases the impacts of recency effect. $^{7,28-30}$

This study emphasizes that the experience of the organizations also decreases recency effect. Experience is a major source of learning in organizations. ${ }^{31}$ Experienced firms can acquire substantial knowledge from past operations. Based on the similar decisionmaking situations they would have encountered in the past, firms can use the knowledge and experience they acquired to analyze and make choices. If a firm has substantial knowledge regarding a specific type of decision, technological decision criteria will be put in place to seek solutions. By contrast, inexperienced firms are unlikely to have real information to determine what type of actions should be adopted and will thus rely more on social cues. ${ }^{1,2}$ The existence of uncertainty often enhances the impact of social factors. ${ }^{2}$ The experience of peer firms is a powerful social indicator influencing its decisions; ${ }^{32}$ hence, it likely influences the decision of an inexperienced firm.

Studies on FDI have indicated the impact of firms' own experience on location choices. Firms' prior investment experiences in a country have a highly positive impact on their propensity to invest in a specific country. ${ }^{33}$ A firm with prior investment experience in a country has substantial knowledge to evaluate that country's opportunities/threats, ${ }^{34}$ and thus will rely less on location choices of peer firms as a cue to make a decision. By contrast, firms without prior investment experiences in a specific country are less likely to possess relevant information for making investment decisions. Despite the opportunities to access the market and of having customer information of the specific country, firms without prior investment experiences are unlikely to develop an evaluation system that will enable them to analyze the information. ${ }^{17}$ Therefore, these firms may be uncertain about their decision to enter the country; the recent moves of peer firms would then become vital cues for them to make decisions. Therefore, the following hypothesis is proposed:

Hypothesis 3(H3): A firm's investment experiences in a specific country will negatively moderate $H 1$.

Figure 1 depicts the conceptual framework of this study. Please note that results presented in Section 4.1 should be consulted for the following two constructs in Figure 1: 'The firm's own FDI experience' and Peer firms' remote FDI'.

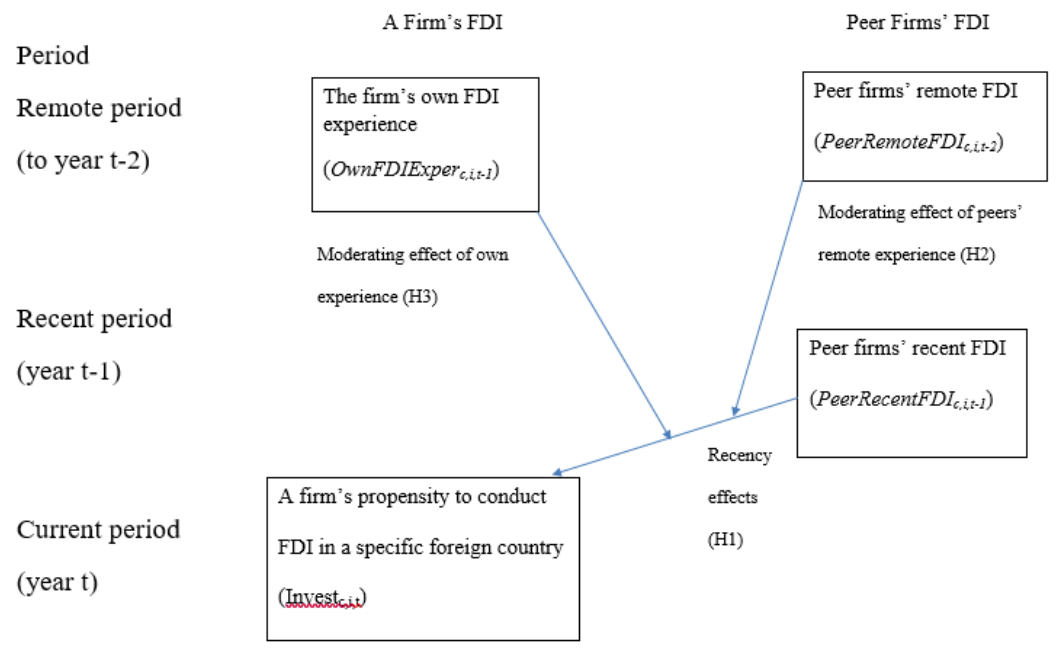

Figure 1: The Conceptual Framework. 


\section{Methodology}

\subsection{Data collection}

The samples used in this study are obtained from the FDI of listed companies of four industries in Taiwan: the textile, electrical machinery, iron and steel, and firms engaged in FDI on 1,344 occasions in 22 countries/regions: the textile industry with 58 firms, the electrical machinery industry with 29 firms, the iron and steel industry with 27 firms, and the electronics industry with 96 firms. Table 1 shows the distribution of FDIs among the countries/regions of the four industries. Of the 22 countries/regions, mainland China and Hong

Table 1. Country/region distribution of listed companies in Taiwan's textiles, electrical machinery, iron and steel, and electronics industries from 1994 to 2001.

\begin{tabular}{|c|c|c|c|c|c|c|c|c|c|c|c|}
\hline & Hong Kong & Malaysia & Philippines & Indonesia & Singapore & Thailand $\mathrm{s}$ & buth Kore & Mexico & France & Italy & USA \\
\hline Textiles & 40 & 8 & 7 & 19 & 7 & 9 & 0 & 0 & 0 & 0 & 20 \\
\hline Electrical machinery & 20 & 16 & 5 & 5 & 20 & 2 & 2 & 0 & 4 & 6 & 40 \\
\hline Iron and steel & 0 & 6 & 0 & 8 & 15 & 0 & 0 & 0 & 0 & 0 & 31 \\
\hline Electronics & 76 & 49 & 21 & 0 & 99 & 52 & 7 & 6 & 18 & 4 & 315 \\
\hline Total & 136 & 79 & 33 & 32 & 141 & 63 & 9 & 6 & 22 & 10 & 406 \\
\hline & Canada & U.K. & Australia & Ireland & Germany & S. Arabia & Japan & India & \multicolumn{3}{|c|}{ Brazil Mainland China Netherlands } \\
\hline Textiles & 0 & 11 & 0 & 0 & 10 & 0 & 6 & 2 & 0 & 19 & 0 \\
\hline Electrical machinery & 0 & 10 & 0 & 0 & 10 & 0 & 3 & 0 & 0 & 14 & 2 \\
\hline Iron and steel & 0 & 8 & 0 & 0 & 0 & 0 & 2 & 0 & 0 & 6 & 0 \\
\hline Electronics & 18 & 50 & 8 & 6 & 47 & 4 & 92 & 0 & 6 & 21 & 52 \\
\hline Total & 18 & 79 & 8 & 6 & 67 & 4 & 103 & 2 & 6 & 60 & 54 \\
\hline
\end{tabular}

Source: Annual reports of listed companies

electronics industries. The observations span a period from 1994 to 2001. The four industries are investigated for two reasons. First, they are all essential industries in Taiwan, and therefore represent Taiwan's economic development. Second, they are heterogeneous regarding production technology and industry fluctuation, and thus increase the generality of this study. Listed companies, rather than all companies in the industry, are investigated because of data availability. It is assumed here that listed companies in an industry constitute a reference group in which they imitate each other.

The FDI data are derived from the annual reports of the listed companies. Such data are credible because listed companies must report their FDI to the government of Taiwan and thus it becomes difficult for them to conceal any FDI. The observation period comprises 210 firms from four industries, and these
Kong are excluded because their policy risk indices, which were proposed by Henisz (2000) ${ }^{35}$ and serve as control variables here, cannot be obtained. The unit of analysis used here is firm-country-year. The recent period is defined as the 2-year-period before the observation year, whereas the remote period indicates the time period before the recent period. The total number of observations is 20,691 .

\subsection{Measurement}

Dependent variable. Whether firm i invests in country $c$ in year $t$ (Invest $t_{c, i t}$ ). The dependent variable is coded as 1 if the firm $\mathrm{i}$ has a new investment in the country $\mathrm{c}$ in the year $t$; otherwise, it is coded as 0 .

Independent variable. The number of peer firms' recent FDI in the country $c$ (PeerRecentFDI $\left.I_{c, i, t-1 \&_{2}}\right)$ calculates the natural algorithm of 1 and the total 
amount of FDI invested by listed companies, rather than the firm $i$, in the years $t-1$ and $t-2$ in the country c. ${ }^{1}$

Moderating variable. Remote period here is defined as the period before the end of year $\mathrm{t}-3$. The number of peer firms' FDI in the country $c$ in the remote period (PeerRemoteFDI $I_{c, i, t-3}$ ) calculates the natural algorithm of 1 and the total amount of FDI invested by listed companies, rather than the firm $i$, by the end of year $t-3$ in the country $c$. Another moderating variable, a firm's own FDI experiences in the country $c$ $\left(\right.$ OwnFDIExper $\left._{c, i, t-1}\right)$, is coded as 1 if the firm $i$ had FDI in the country $\mathrm{c}$ before the end of the year $t-1$; otherwise, it is coded as 0 .

Control variable. Three categories of control variables are included: host country, firm, and dummy variables.

Control variables associated with the host country include policy risk, growth of per capita GDP, and cultural distance. The degree of policy risk (PoliRisk $\left.k_{c, t}\right)$ of a country influences the attention of the participating country The variable is measured using the policy risk index, as proposed by Henisz (2000) ${ }^{35}$, which presents the extent of how often the government changes its policies. Each country has a value for each year, ranging from 0 to 1 , where 0 indicates that the country has the lowest policy risk index in a certain year. Growth of per capita GDP $\left(G r G D P_{c, t}\right)$ captures another dimension of the country's attractiveness, measured as (per capita $G D P_{i, t}$ per capita $\left.G D P_{i, t-1}\right) /$ per capita $G D P_{i, t-1}$. The data are derived from the World Economic Outlook Database issued by the IMF. Cultural distance between the host country and Taiwan $\left(\mathrm{CulDis}_{c}\right)$ represents the cultural similarities between them, which would influence the tendency of firms to invest in the host country. This study uses data reported by Hofstede $(1980)^{36}$ to measure the cultural distance.

Control variables at the firm level include size, age, R\&D intensity, and the debt ratio. Larger firms usually have more slack resources for investment. Firm size $\left(\right.$ Size $\left._{i, t}\right)$ is measured as the logarithmic value of the

\footnotetext{
${ }^{1}$ The recent period is defined as containing years $t-1$ and $t-2$, rather than only year $\mathrm{t}-1$, for two reasons. First, a short period of 1 year cannot reflect the fact that firms need time to launch FDI. Second, if the recent period is defined as year $\mathrm{t}-1$, a collinearity problem would exist between peer firms' recent FDI and remote FDI. Moreover, if the recent period is defined as containing year $t-1, t-2$, and $t-3$, the directions and significant levels of hypotheses remain the same.
}

number of employees of the firm $i$ at the year $t-1 .^{2}$ Younger firms are less inert and thus more likely to bear the risk from FDI. Firm age $\left(A g e_{i, t}\right)$ is measured as the period from the firm $i$ 's year of establishment to the year $t$. Firms putting more resources into R\&D would be more likely to seek foreign markets to utilize their technological capability. Thus, R\&D intensity $\left(\right.$ RDInten $\left._{c, t}\right)$ is controlled and measured as the firm $i$ 's $\mathrm{R} \& \mathrm{D}$ expenditure divided by the sales in the year $t$. Firms with higher debt ratios have higher financial leverage, which reduces the firms' willingness to bear further risk, and thus might weaken their capability to engage in FDI. Debt ratio $\left(D e b R a_{i, t}\right)$ is measured by dividing the firm $i$ 's total amount of debt by the total asset in the year $t$.

\subsection{Model specification}

This study analyzes whether a firm would invest in a specific country in a certain year. Because the structure of the data collected here consists of both pooled time series and cross-sectional data, a maximum likelihood estimator for the random effects logit regression is used to deal with such data structure.

\section{Results}

Table 2 shows the descriptive statistics and correlation coefficients for all variables. Although a high correlation (0.8762) exists between PeerRecentFDI $I_{c, i, t-1}$ and PeerRemoteFDI $I_{c, i, t-2}$, collinearity tests (variance inflation factor and condition index) indicate that the collinearity problem does not exist.

Table 3 presents the estimation results. Model 1 shows the coefficient estimates for the control variables only, showing that the probability of a firm investing in a certain country will be higher, as the targeted country has less policy uncertainty and lower GDP growth. In addition, firms with larger scale, younger age, higher R\&D intensity, and lower debt ratio are more likely to undertake FDI. However, only policy uncertainty and cultural distance have stable impact among different models.

Model 2 adds PeerRecentFDI $I_{c, i, t-l \& 2}$ to examine Hypothesis 1 that predicts a positive relationship

\footnotetext{
${ }^{2}$ Another size measurement, the logarithmic value of sales, is also alternatively used in empirical models. The results show no significant difference among all of the independent and moderating variables
} 
between peer firms' recent FDI in a specific country and a firm's propensity to invest in that country. Consistent with Hypothesis 1, the coefficient is positive and significant $(p<.001)$. It supports the existence of recency effect.

Model 3 includes PeerRemoteFDI $I_{c, i, t-3}$ and OwnFDIExper $_{c, i, t-l}$. Results show that the remote FDI experience of peer firms does not have significant impact, whereas a firm's own FDI experience does. Model 4 further includes the interaction of PeerRecentFDI $I_{c, i, t-1 \notin 2}$ and PeerRemoteFDI $I_{c, i, t-3}$ to examine Hypothesis 2. Hypothesis 2 predicts that the coefficient is negative and significant $(\mathrm{p}<.001)$, indicating that recency effect becomes weaker as the number of FDIs of peer firms before the recent period increases. Model 5 further adds the interaction of PeerRecentFDI $_{c, i, t-1}$ and OwnFDIExper ${ }_{c, i, t-l}$ to examine Hypothesis 3, which emphasizes the negative moderating effects of firms' own experiences on recency effect. The coefficient is negative and significant $(\mathrm{p}<.05)$ and supports Hypothesis 3 . Model 6 includes the two interaction terms jointly, and the results do not change.

Regarding the control variables, policy risk and cultural distance exhibit a consistent pattern in their direction and significance among the four models. Policy risk has a negative effect on firms' propensities to invest, which indicates that the political environment of the host countries has a significant influence on firms' FDI location choices. Regarding the cultural distance, it is surprisingly positively associated with firms' propensities to conduct FDI. The reason may be Taiwan's distinct historical and political relationship with some countries. For instance, the United States (406 FDI) provides export markets to Taiwan; Singapore (141 FDI) has a good, long-term political relationship with Taiwan; and Japan (103 FDI) had governed Taiwan and thus, to date, keeps close economic relationship with Taiwan. Of these three countries where Taiwan has more FDI, the United States has greater cultural distance with Taiwan, thus proving that the greater cultural distance is associated with more FDI.

\subsection{Fixed-effects analysis}

In addition to the random effects logit regression, a fixed-effects logit regression is also conducted here. Four sets of dummy variables are included. First, six regional dummy variables are included to control for factors such as transportation cost. The countries listed in Table 1 are classified into seven groups: South Asia, Southeast Asia, Northeast Asia, Europe, Australia, North America and Mexico, South America, and middle East. Second, three industry dummy variables are used to control inter-industry effects on FDI. Third, year dummy variables are adopted to control potentially different tendencies of firms to engage in FDI over different years, thereby capturing the effects of factors such as exports/imports and the GDP growth of Taiwan. Finally, firm dummy variables are used to control firmspecific factors.

Table 2. Descriptive statistics and correlation coefficients.

\begin{tabular}{|c|c|c|c|c|c|c|c|c|c|c|c|c|c|}
\hline & & Mean & STD. & 1 & 2 & 3 & 4 & 5 & 6 & 7 & 8 & 9 & 10 \\
\hline 1 & Invest $_{\mathrm{c}, \mathrm{i}, \mathrm{t}}$ & .050 & .223 & & & & & & & & & & \\
\hline 2 & PeerRecentFDI $I_{c, i, t-1}$ & 3.900 & 10.955 & .432 & & & & & & & & & \\
\hline 3 & PeerRemoteFDI $\mathrm{I}_{\mathrm{c}, \mathrm{i}, \mathrm{t}-2}$ & 6.477 & 19.516 & .419 & .962 & & & & & & & & \\
\hline 4 & OwnFDIExper $_{\mathrm{c}, \mathrm{i}, \mathrm{t}-1}$ & .040 & .199 & .823 & .416 & .416 & & & & & & & \\
\hline 5 & PoliUncer $_{\mathrm{c}, \mathrm{t}}$ & .648 & .178 & -.142 & -.209 & -.178 & -.125 & & & & & & \\
\hline 6 & $\mathrm{GrGDP}_{\mathrm{c}, \mathrm{t}}$ & 1.618 & 11.330 & -.015 & -.031 & -.051 & -.019 & -.051 & & & & & \\
\hline 7 & $\mathrm{CulDis}_{\mathrm{c}}$ & 36.806 & 22.110 & .117 & .185 & .160 & .104 & -.093 & .029 & & & & \\
\hline 8 & Size $_{\mathrm{i}, \mathrm{t}}$ & 6.561 & .993 & .065 & .100 & .100 & .064 & .010 & -.031 & .000 & & & \\
\hline 9 & $\mathrm{Age}_{\mathrm{i}, \mathrm{t}}$ & 21.530 & 10.756 & -.047 & -.089 & -.066 & -.036 & .016 & -.049 & .000 & .068 & & \\
\hline 10 & RDInten $_{c, t}$ & .021 & .033 & -.007 & -.010 & -.009 & -.006 & -.006 & .023 & .000 & .074 & -.012 & \\
\hline 11 & $\operatorname{DebRa}_{\mathrm{i}, \mathrm{t}}$ & 41.721 & 15.523 & -.014 & -.032 & -.031 & -.010 & -.006 & .033 & .000 & .023 & .086 & .061 \\
\hline
\end{tabular}

$\mathrm{N}=22,536$. Absolute values greater than 0.19 are significant at $\mathrm{p}<.01$; absolute values greater than 0.14 are significant at $\mathrm{p}<.05$ 
Table 3. Random effect discrete time logit analysis.

\begin{tabular}{|c|c|c|c|c|c|}
\hline Variable & $\begin{array}{c}\text { Hypothesis } \\
\text { (expected sign) }\end{array}$ & Model 1 & Model 2 & Model 3 & Model 4 \\
\hline PeerRecentFDI $_{c, i, t-1}$ & $\mathrm{H} 1(+)$ & & $0.027 * * *(0.002)$ & $0.062 * * *(0.006)$ & $0.062 * * *(0.006)$ \\
\hline PeerRecentFDI $I_{c, i, t-1} \times$ Invest $_{c, i, t} / 100$ & $\mathrm{H} 2(-)$ & & & $-0.023 * * *(0.003)$ & $-0.032 * * *(0.003)$ \\
\hline OwnFDIExper $_{c, i, t-1}$ & & & & & $6.960 * * *(0.211)$ \\
\hline PeerRecentFDI $I_{c, i, t-1} \times$ OwnFDIExper $_{c, i, t-1}$ & $\mathrm{H} 3(-)$ & & & & $-0.023 * *(0.007)$ \\
\hline PoliUncer $_{c, t}$ & & $-2.645 * * *(0.199)$ & $-2.032 * * *(0.204)$ & $-1.654 * * *(0.211)$ & $-1.654 * * *(0.211)$ \\
\hline $\mathrm{GrGDP}_{\mathrm{c}, \mathrm{t}}$ & & $-0.004(0.005)$ & $-0.003 \quad(0.005)$ & $-0.003 \quad(0.005)$ & $-0.003(0.005)$ \\
\hline CulDis $_{\mathrm{c}}$ & & $0.069 * * *(0.003)$ & $0.048 * * *(0.003)$ & $0.040 * * *(0.003)$ & $0.040 * * *(0.003)$ \\
\hline Size $_{i, t}$ & & $0.136 * * *(0.034)$ & $0.141 * * *(0.036)$ & $0.142 * * *(0.036)$ & $0.062 * * *(0.059)$ \\
\hline Age $_{i, t}$ & & $-0.016 * * *(0.004)$ & $-0.018 * * *(0.004)$ & $-0.018 * * *(0.004)$ & $-0.017 * * *(0.007)$ \\
\hline RDInten $_{c, t}$ & & $0.000 \quad(0.000)$ & $0.000 \quad(0.000)$ & $0.000 \quad(0.000)$ & $0.000 \quad(0.000)$ \\
\hline $\operatorname{DebRa}_{\mathrm{i}, \mathrm{t}}$ & & $0.000 \quad(0.002)$ & $0.000 \quad(0.002)$ & $0.000 \quad(0.002)$ & $0.000 \quad(0.004)$ \\
\hline Region dummies & & Yes & Yes & Yes & Yes \\
\hline Industry dummies & & Yes & Yes & Yes & Yes \\
\hline Firm dummies & & Yes & Yes & Yes & Yes \\
\hline Year dummies & & Yes & Yes & Yes & Yes \\
\hline Log likelihood & & -3282 & -3204 & -3181 & -1454 \\
\hline Percentage correct & & 94.9 & 95.0 & 95.0 & 98.3 \\
\hline
\end{tabular}

$\mathrm{N}=22,536 ; * \mathrm{p}<.05, * * \mathrm{p}<.01, * * * \mathrm{p}<.001$

\section{Discussion and Conclusion}

\subsection{Research summary}

This study finds that if a large number of firms adopt a specific type of action at the same time, a mimetic pressure appears to prompt a firm to take the same action. Many studies confirm that the experiences of peer firms have imitation consequences on the behavior of a firm. ${ }^{17,19}$ FDI is a complex decision in which recency effect easily occur. ${ }^{20}$ Therefore, this study examines FDI as the research target and applies recency effect to determine whether the recent FDIs of peer firms arouse the imitation reaction of a firm. Results corroborate the hypotheses and further indicate two moderating factors: peer firms' remote FDI and the firm's own FDI experience.

\subsection{Contributions to the literature}

This study offers several contributions. First, it applies recency effect to imitation studies. Such an application takes into consideration that the experience of peer firms in different periods would result in different imitation effects. The time factor is critical for theory construction. ${ }^{37}$ Clarification of the time factor helps to enrich the theory, ${ }^{38}$ which past imitation studies often neglected. This study observes that the recent FDI experience of peer firms yields significant imitation effects, which are distinct from previous studies that have examined imitation effects based on the experience of all peer firms. According to the findings of this study, his distinction is relevant because although the two industries may have the same amount of peer-firm experience, the imitation behavior would more likely occur in the industry in which experience was obtained more recently than in the other.

However, if recency effect persists, a case often neglected in previous studies would emerge: If a frequency-based imitation mechanism exists and starts to function, the Matthew effect would appear: Widely adopted actions would be repeatedly adopted, resulting in behavioral patterns in an industry that would converge to an extremely small number of types. Nevertheless, not all industries appear so in practice. The findings of this study explain why not all industries experience the Matthew effect. According to Hypothesis 1 , the new FDI in a specific country in the year $\mathrm{t}$ by peer firms pushes a firm to conduct new FDI in that country in the year $t+1$, and the new FDI in the year $t+1$ increases the likelihood for other firms to invest in that country in the year $t+2$. However, according to Hypothesis 2, the FDI of peer firms conducted before the year $t+1$ would weaken imitation effects yielded from new FDI in the year $t+1$. Without the weakening 
process, the Matthew effect would occur. In addition, according to Hypothesis 3, a firm's own FDI experience in a specific country also weakens imitation effects yielded from the FDI experience of peer firms. The two moderators make the increase of FDI in a specific country unlikely to proceed without an end, and thus a built-in moderating mechanism would exist in a frequency-based imitation, which prevents the Matthew effect from occurring.

\subsection{Practical implications}

Firms often imitate others in order to make new and innovative managerial decisions and/or to introduce new products and services. Imitation effects resulting from recent events can be lessened by peer firms' remote experience and firms' own experience, which illustrates the importance of attention and decision makers' judgment in complex decisions. Events attracting more attention can arouse stronger imitation effects. However, if the frequency of occurrence of similar events was so high in the past that the events would have become highly routinized, recent events would not attract much attention, and thus not arouse imitation. Experienced firms often have sufficient information and knowledge to make decisions based on their technical consideration, rather than other firms' actions. Therefore, imitation effects of recent events would be weakened.

From the aspect of a long-term angle, two consequences would take place as numerous peer firms conduct FDI in the earlier period in a specific country. The first consequence, based on recency effect, is that the possibility for firms to continue conducting FDI in a specific country in the next period would be increased. The second consequence is that those FDIs in the earlier period would form a background, which enhances the degree of routinization of FDI in the next period. Additionally, many firms having FDI in a specific country would lessen the recency effect on subsequent FDI in the next period. Therefore, FDI in a specific country would increase and decrease. Regarding the observation period (1994-2001) of this study, in 1994, firms in the four industries had FDI in 10 countries. But in 2001, of the 10 countries, the ratio of FDI frequency to all FDIs conducted by firms in four industries decreased in five countries. Evidently, in countries where firms have FDI in an early period, the probabilities of firms conducting FDI in the countries may become lower in a later period.

\subsection{Limitations and future research}

This study has three limitations. First, it does not consider the imitation effects of each level of FDI performance. Success often implies legitimacy and value creation, and thus firms often imitate other successful firms. The difficulty in measuring the performance of each FDI constitutes a limitation of this study. Second, this study assumes that the listed companies treat each other as members of a reference group which firms takes as a standard in measuring success. Although this assumption is often accepted, it is still worth re-examining in future studies. Third, firms may have several ways of engaging in foreign markets, such as undertaking critical investment evaluation processes and/or forming a foreign strategic alliance, which might influence the FDI decisions of firms ${ }^{39,} 40$. Because of the limitations on data accessibility, this study investigates only the experience in engaging in FDI. Further research could broaden the scope into various ways of engaging in foreign markets.

\section{References}

1. P. R. Haunschild and A. S. Miner, Modes of interorganizational imitation: The effects of outcome salience and uncertainty, Adm. Sci. Q. 42(3) (1997) 472500 .

2. P. J. DiMaggio and W. W. Powell, The iron cage revisited: Institutionalism isomorphism and collective rationality in organizational fields, Am. Sociol. Rev. 48 (1983) 147-160.

3. P. Ingram and J. A. C. Baum, Opportunity and constraint: Organizations' learning from the operating and competitive experience of industries, S. M. J. 18(1) (1997) 75-98.

4. J. A. C. Baum and P. Ingram, Survival-enhancing learning in the Manhattan hotel industry, 1898-1980. Manage. Sci. 44(7) (1998) 996-1016.

5. J. Gimeno, R. Hoskisson, B. Beal and W. Wan, Explaining the clustering of international expansion moves: A critical test in the U.S. telecommunications industry, Acad. Manage. J. 48(2) (2005) 297-319.

6. J. Kerstholt and J. Jackson, Judicial decision making: Order of evidence presentation and availability of background information, Appl. Cogn. Psychol. 12(5) (1998) 445-454. 
7. P. Reckers and G. Schultz, The effects of fraud signals, evidence order and group assisted council on independent auditor judgment, Behavioral Research in Accounting. 5 (1993) 124-144.

8. K. E. Weick, Cognitive Processes in Organizations. in B. M. Staw (ed.), Research in Organization Behavior, 1 (JAI Press, Greenwich, CT, 1979), pp. 41-74.

9. R. K. Merton, The Matthew effect in science. Science. 159(3810) (1968) 56-63.

10. P. Grindley, Standards Strategy and Policy (Oxford University Press, New York, NY, 1995).

11. M. L. Katz and C. Shapiro, Network externalities, competition, and compatibility. Am. Eco. Rev. 75(3) (1985) 424-440.

12. E. L. Thorndike, Animal intelligence: An experimental study of the associative processes in animals, Psychological Review Monograph Supplement. 2(4) (1898) 1-8.

13. R. M. Cyert and J. G. March, A Behavioral Theory of the Firm (Prentice Hall, Englewood Cliffs, NJ, 1963).

14. D. A. Levinthal and J. G. March, The myopia of learning, Strat Manage J. 14(Winter Special Issue) (1993) 95-112.

15. E. Mansfield, Technical change and the rate of imitation, Econometrica. 29(4) (1961) 741-766.

16. H. R. Greve, Managerial cognition and the mimetic adoption of market positions: What you see is what you do, Strat. Manage. J. 19(10) (1998) 967-988.

17. W. J. Henisz and A. Delios, Uncertainty, imitation, and plant location: Japanese multinational corporations, 1990-1996, Adm. Sci. Q. 46(3) (2001) 443-475.

18. S. J. Chang and P. M. Rosenzweig, The choice of entry mode in sequential foreign direct investment, Strat. Manage. J. 22(8) (2001) 747-776.

19. M. F. Guillén, Structural inertia, imitation, and foreign expansion: South Korean firms and business groups in China, 1987-1995, Acad. Manage. J. 45(3) (2002) 509525.

20. R. Hogarth and H. Einhorn, Order effects in belief updating: The belief-adjustment model, Cog. Psychol. 24(1) (1992) 1-55.

21. A. Ashton and R. Ashton, Sequential belief revision in auditing, The Accounting Review. 63(4) (1988) 623-641.

22. S. K. Asare, The auditor's going concern opinion decision: Interaction of task variables and the sequential processing of evidence, The Accounting Review. 67(2) (1992) 379-393.

23. A. Furnham, The robustness of the recency effect: Studies using legal evidence, J. Gen. Psychol. 113(4) (1986) 351-357.

24. W. Ocasio, Toward an attention-based view of the firm, Strat. Manage. J. 18(S1) (1997) 187-206.
25. A. Tversky and D. Kahneman, Rational choices and framing of decisions, J. Bus. 59(4) (1986) 251-284.

26. L. Ross and R. E. Nisbett, The Person and the Situation: Perspectives of Social Psychology (McGraw-Hill, New York, NY, 1991).

27. A. J. Hoffman and W. Ocasio, Not all events are attended equally: Toward a middle-range theory of industry attention to external events, Organization Science. 12(4) (2001) 414-434.

28. W. F. Messier. Jr. and R. M. Tubbs, Recency effect in belief revision: The impact of audit experience and the review process, Auditing. 13(1) (1994) 57-72.

29. B. K. W. Pei, S. Reed and B. Koch, Auditor belief revision in a performance auditing setting: an application of the belief adjustment model, Accounting, Organization and Society. 17(2) (1992) 169-183.

30. K. T. Trotman and A. Wright, Recency effect: Task uncertainty, decision mode, and task-specific experience, Behavioral Research in Accounting. 8 (1996) 175-193.

31. E. T. Penrose, The Theory of Growth of the Firm (Wiley, New York, NY, 1959).

32. J. M. Podolny, Market uncertainty and the social character of economic exchange, Adm. Sci. Q. 39(3) (1994) 458-483.

33. S. J. Chang, International expansion strategy of Japanese firms: Capability building through sequential entry, Acad. Manage. J. 38(2) (1995) 383-407.

34. H. G. Barkema, J. H. J. Bell and J. M. Pennings, Foreign entry, cultural barriers, and learning, Strat. Manage. J. 17 (1996) 151-166.

35. W. J. Henisz, The institutional environment for economic growth, Economics and Politics. 12(1) (2000) 1-31.

36. G. Hofstede, Culture's Consequences: International Differences in Work-Related Values (Sage Publications, Beverly Hills, CA, 1980).

37. D. G. Ancona, P. S. Goodman, B. S. Lawrence and M. L. Tushman, Time: A new research lens, Acad. Manage. Rev. 26(4) (2001) 645-663.

38. J. M. George and G. R. Jones, The role of time in theory and theory building, J. Manage. 26(4) (2000) 657-684.

39. C. Lin, Y. Huang, G. Jalleh, Y. Liu and M. Tung, An Exploratory Study of Factors Affecting Adoption and Implementation of B2B E-Commerce in Australian Health Care Organizations, International Journal of Electronic Commerce Studies, 1(2) (2010) 77-96.

40. C. Lin and G. Pervan, IS/IT Investment Evaluation and Benefits Realisation Issues in a Government Organisation, Proceedings of the Twelfth Australasian Conference on Information Systems (ACIS 2001), (Coffs Harbour, NSW, Australia, 2001), 5-7 December, pp. 379386 